Case Reports

\title{
An Economic and Environmental Evaluation of the Em-Ferro Plastic Sorting Technology
}

\author{
Seyedehfarzaneh Nojabaei, Omid Nematshahi and Matthew Franchetti \\ Department of Mechanical, Industrial and Manufacturing Engineering (MIME), \\ The University of Toledo, Toledo, OH 43606 USA
}

\author{
Article history \\ Received: 15-03-2015 \\ Revised: 3-04-2015 \\ Accepted: 30-04-2015
}

Corresponding Author: Seyedehfarzaneh Nojabaei Department of Mechanical, Industrial and Manufacturing Engineering (MIME), The University of Toledo, Toledo, $\mathrm{OH}$ 43606, USA

Email: nojabaeifarzaneh528@gmail.com

\section{Introduction}

\section{Importance of Research}

The increase in natural resources consumption as well as the detrimental environmental impacts of traditional waste disposal methods has led to a growing attention towards recycling as a means to reduce both resource consumption and adverse environmental impacts. Recycling offers significant advantages from an

\begin{abstract}
Recycling has been continually practiced since the dawn of mankind; however, increasing production costs as well as environmental impacts of the conventional waste disposal methods have shed a light on the importance of recycling as a sustainable way to produce goods and services. Recycling has proven to be beneficial, economically and environmentally: It saves resources, prevents pollution, supports public health and creates jobs. Recycling can be applied to different materials present in the Municipal Solid Waste (MSW). Plastics constitute a substantial portion of the MSW. In 2012, plastics accounted for $12.7 \%$ of the total MSW generated in the United States. However, only of the total amount of plastic generated in 2012 was recovered for recycling. Currently, the major part of the plastics generated is disposed of through incineration or landfilling. These conventional disposal methods impose serious threats to the environment such as greenhouse gas emission and soil and underground water contamination. These effects along with the versatility of the plastic waste have led the development of more environmental friendly plastic recycling methods. Prior to recovery, the plastic waste should be sorted into the different plastic types it is composed of. Traditional plastic sorting methods used optical or manual sortation which was not only costly but also susceptible to high nonconformance rates. Newer technologies have been developed that have higher output and are more economically justifiable. This thesis performs and economical and environmental comparison between five plastic sorting methods that are currently in use and one emerging technology which uses Electromagnetic (EM) waves and ferrofluid to sort plastics. Economic Input-Output Life Cycle Assessment (EIO-LCA) is the method used to collect the data and perform the analyses. Two economic measures are used to evaluate the methods from an economical point of view. The objective is to study how the new method compares to the existing methods both economically and environmentally using a case study in Toledo, Ohio. The data related to cost, energy requirements and carbon emissions were collected through contacting local vendors. The results of the study showed that all of the methods have positive economic performance with minor variations in energy use and carbon emissions.
\end{abstract}

Keywords: Economic Analysis, Waste Management, Plastic Recycling, LCA economical and environmental point of view. Through recycling, it is possible to avoid the costs of resource extraction and virgin material production and reduce the environmental impacts of waste disposal imposed by waste disposal systems such as landfilling and incineration.

The United States is the leading country in Municipal Solid Waste (MSW) production in the world. The MSW generation in the US has increased from 151.6 million tons in 1980 to 251 million tons in 2012 which shows a 
$65 \%$ increase (EPA, 2014a). Recycling rate of MSW generated has increased from 9.6 to $34.5 \%$ in the same period of time. According to EPA, the MSW generated in the US is composed of 9 major components:

- Paper and paperboard

- Food waste

- Yard trimmings

- Plastics

- Metals

- Rubber, leather and textiles

- Wood

- Glass

- Other

Plastics compose a major part of the total MSW generated $(12.7 \%$ in 2012). The long degradation processes of plastic as well as the environmental impacts of its disposal by means of traditional methods have led to an increased attention to plastic recycling. In 2012, only $8.8 \%$ of the plastics generated had been recovered (EPA, 2014a). Plastics recovering process consists of three main stages: Collection, sortation and recovery. Frist, the plastic waste is collected from curbside recycling bins or drop-off sites. Then, it is sent to sorting facilities where each type of plastic is separated using sortation methods. Once sorting is done, plastics are baled and sent to recovering facilities where they are washed and ground into small flakes. After further cleaning, the flakes are dried, melted, filtered and formed into pellets which are then shipped to manufacturing plants and used for different applications (EPA, 2014b). To be able to be utilized, the outgoing plastic pellets must have a certain degree of consistency and purity. Therefore, plastic sorting technologies have enjoyed a lot of attention in the past two decades in order to yield more precise sortation technologies which lead to optimal purity and consistency.

\section{Objective}

The objective of this study is to primarily evaluate the EM-Ferro plastic separation technology from an economic and environmental point of view and secondarily, to compare this new technology with some existing plastic sorting technologies. The EM-Ferro method operates on the basis of the fact that electromagnetic waves can change the density of a ferrofluid which allows for separation of different plastic types. This research evaluates the economic and environmental implications of this new method and carries out a comparison between this method and five other emerging post-consumer plastic sorting methods to find out whether this method is economically viable and environmentally preferable when up scaled. The research carries out economic and environmental analyses using the estimates collected from vendors and provides rankings in three categories which might be utilized in public or private applications.

\section{Current Technologies for Plastic Sortation}

There are currently five plastic sorting technologies in use by the recycling industry. These methods use different technologies to sort plastics. These five methods are known as electrostatic separation, the sink/swim differential method, surfactant based separation, near-infrared scanning and ultrasound scanning (Franchetti and Kress, 2013). This section will provide a brief overview of how these methods work. In addition, we will also introduce the new EM-Ferro plastic sorting method which uses electromagnetic waves and ferrofluid to sort plastic particles.

\section{Electrostatic Separation}

Electrostatic separation was first developed in the 1990's as an example of an electrically based solution to sorting plastic particles. In this method, plastic particles are first statically charged by friction and then introduced to an electrostatic field with two oppositely charged electrodes. Different plastic types tend to take different electrostatic charges as shown in Table 1. The particles are then sorted in different bins based on their charges.

There are six components in a triboelectric separator: A feeder system, a blower, a cyclone shaped tunnel for the triboelectric friction to occur, assorted containers for collecting sorted plastic bins and two vertical-plate electrodes along with their accompanying DC power supply (Dodbiba et al., 2006). The system is installed inside a temperature and humidity control chamber whose duty is to keep temperature and humidity constant. Plastic particles are fed to the tribo-cyclone using an air current provided by a blower. The air flow transports the particles into the tribo-cyclone and frictionally charges them by rubbing them against the inner lining of the cyclone. After enough time being statically charged in the cyclone, the air flow feed is switched off and the particles fall into the electrostatic field generated by the two oppositely charged electrodes.

The particles are deflected towards the two electrodes based on their charge and then collected into the assigned bins. The particles with insufficient charge are collected in the central bins.

\section{Sink/Swim Differential Method}

The first studies on plastic flotation were carried out in 1970's. The principle used in this separation method is very straightforward. Plastic particles are mixed with a liquid of known density in a container. Different plastic types have different density ranges as shown in Table 2. 
Table 1. Charge propensity of different plastic types

\begin{tabular}{ll}
\hline Plastic type & Triboelectric charge \\
\hline $\begin{array}{l}\text { Acrylonitrile-butadiene-styrene, ABS } \\
\text { Polyethylene terephthalate, PET }\end{array}$ & Positive (+) \\
& $\downarrow$ \\
Polystyrene, PS & \\
Polyethylene, PE & \\
Polypropylene, PP & \\
Polyvinyl chloride, PVC & Negative (-)
\end{tabular}

Table 2. Density ranges for the different plastic types

\begin{tabular}{ll}
\hline Material & Density range $\left(\mathrm{g} / \mathrm{cm}^{3}\right)$ \\
\hline Polypropylene & $0.916-0.925$ \\
Low-Density Polyethylene & $0.936-0.955$ \\
High-Density Polyethylene & $0.956-0.980$ \\
Bulk Polystyrene & $1.050-1.220$ \\
Polyvinyl Chloride & $1.304-1.336$ \\
Polyethylene Terephthalate & $1.330-1.400$ \\
\hline
\end{tabular}

The specific value of the liquid density allows different types of plastic particles to sink or swim based on their relative densities. The denser particles sink while the less dense particles rise to the surface of the liquid. Although this method is very straightforward in concept, only a few scale applications of this method exist; however, it has been receiving more attention in the past few years (Al-Salem et al., 2009). The main problem in this method is that different plastic types do not have a substantial difference in density. To address issue, two major solutions have been proposed. The first solution is to use liquids with pressure-variant densities. Pressure-variant liquids are liquids whose density changes relative to the container pressure. Being able to change the density of the liquid through changing the pressure of the container allows for a more accurate separation. This is usually done in a pressurized container and by setting the liquid density to specific values between the densities of plastic particles, higher precisions are attained. The second solution is applying this method in a multiple-stage form where different stages are applied with multiple knowndensity liquids which results in the separation of plastic particles with closer densities (Pongstabodee et al., 2008).

\section{Surfactant Based Separation}

This method use a similar mechanism to the sink/swim method. The difference is in this method the plastic particles are first treated with surfactants or wetting agents and then are mixed with a liquid of known surface tension $(\mathrm{L} / \mathrm{G})$. After the system reaches a stable condition, air in introduced to a system through a pump. This method makes use of the concept of critical surface tension of wetting for a solid (c). $\mathrm{c}$ is defined as "the surface tension of the liquid at which the solid surface exhibits a hydrophobic to hydrophilic transition".
The value of $\mathrm{c}$ is different for different types of plastic. Air bubbles are interested to adhere to plastic particles with lower values of $\mathrm{c}$ which causes them to float to the surface of the liquid whereas plastic particles with higher values of $c$ are reluctant to adhere to the air bubbles which causes them to sink to the bottom (Pongstabodee et al., 2008). The method offers three advantages. The first advantage is that it does not require any particularly advanced technology. Secondly, the chemicals that are used as reagents are often used in chemical processing are not environmentally unfriendly. The third benefit is that this method resolves the problem of the sink/swim's method inability to separate certain types of plastic with overlapping densities such as PVC and PET.

\section{Near-Infrared Scanning}

Near-Infrared (NIR) scanning systems are used widely in recycling industries. NIR separation systems are macro-sorting systems i.e., they work with bulk sizes of plastics such as bottles, containers. The vision machine of the system can identify almost every type of plastic resins (Klopffer, 1997). In NIR plastic sortation, plastic parts are moved one by one on a conveyor belt where the NIR detection systems uses high-speed cameras and infrared light to specify the resin color and density spectrometry of the parts. The mechanism makes use of the fact that each plastic type return certain wavelengths after being exposed to infrared light. By analyzing the returning wavelengths, the system identifies the plastic type. After identification, the parts are optically marked and later removed from the system using ejectors such as high pressure air jets. The main benefit of this method is that surface contaminations of the parts do not hinder the system performance.

\section{Ultrasound Scanning}

One of the most recent technologies utilized in plastic recycling is ultrasound scanning. Similar to NIR systems, ultrasound systems also identify the plastic types through exposing the plastic samples to ultra-sonic waves in water. After identification, the plastics are removed from the line into their respective collection bins. This is typically carried out by a mechanical arm. Ultrasound scanning offers two advantages compared with other plastic sorting methods. Unlike other optical technologies, the ultrasound scanning system can identify plastic densities in non-clear liquids such as ferrofluid. It also builds a 3D-image of the parts which is a unique feature to this approach.

\section{EM-Ferro}

This method is recently developed by a team in MIME department at the University of Toledo. EMFerro method uses electromagnetic waves to separate plastic particles suspended in a ferrofluid. Ferrofluids 
are colloidal liquids in which tiny particles of iron, magnetite or cobalt are suspended. The carrier liquids are usually oils, water, acids, or organic solvents. The interesting property of ferrofluids is that, when exposed to electromagnetic waves, they form temporary domains and thus, the viscosity of the fluid changes. The ability to change the ferrofluid's density through changing the intensity of the electromagnetic waves allows for complete control over the process. By altering the density of the ferrofluid to specific values between the densities of different types of plastic, one can determine which plastic particles rise to the surface and which sink to the bottom. While the electromagnetic field is active, the sorted plastic particles are collected. As soon as the electromagnetic field is switched off, the liquid returns to its normal situation and this allows for further separations. In this method, an iron core electromagnet is used to generate the electromagnet field and the process is done inside an antistatic acrylic vessel. Being new, this method needs more experiments and modifications to reach its optimal performance and throughput.

\section{Literature Review}

\section{Life Cycle Assessment (LCA)}

About 1960s were probably the first years in which the western scientific community really gained vision into the fact that the Earth's resources such as oil, coal, minerals are not infinite. The increasing rate of resource extraction as well as the pollution and detrimental environmental effects caused by its consumption gave rise to the question of can we be more environmental friendly? It was in the 1960 s when the importance of environmental considerations in manufacturing systems was realized and issues such as resource and energy efficiency, pollution control and solid waste were brought to public attention (Vijaya et al., 2009). As a response to this concern, in late 1960s and early 1970s, scientists in Europe and USA started developing a method for assessing all of the environmental impacts associated with a product or service during its entire life cycle (Rebitzer et al., 2004). The first attempt at creating a solid framework for assessing a product's environmental burdens throughout its life cycle was carried out by Harry E.TEASLEY, Jr. who was the manager of the packaging function for Coca-Cola Company. He started investigating to create a method through which we could quantify the energy, material and environmental consequences of a package from cradle to grave which then was considered as the basis of LCA studies in the next decades. The term Life Cycle Analysis (LCA) was coined around 1970 by the Midwest Research Institute (MRI) in the United States while similar studies were being performed in Europe by the Open University in England, EMPA in
Switzerland and Sundstrom in Sweden concentrated on the comparison of packaging options with regards to environmental impacts (Rebitzer et al., 2004). In the 1970s and the 1980s, due to the lack of scientific debates and exchanges, LCA was performed using different methods with different definitions, methodologies and results. The need for a standardized theoretical and practical framework was greatly felt. 1990s was the decade of responding to this need. Society of Environmental Toxicology and Chemistry (SETAC) and the International Organization for Standardization (ISO) began the task of defining and developing standard frameworks for LCA with the latter focusing on developing a standard framework for LCA and the former concentrating on developing and harmonizing LCA methods (Williams, 2009). The result of these efforts can be seen in the form of SETAC "Code of Practice" and two international standards developed by ISO:

- ISO 14040 (2006E): 'Environmental managementLife cycle assessment-Principles and framework'

- ISO 14044 (2006E): 'Environmental managementLife cycle assessment-Requirements and guidelines' (Williams, 2009) +

\section{What is LCA?}

According to ISO, LCA is defined as: "Compilation and evaluation of the inputs, outputs and the potential environmental impacts of a product system throughout its life cycle" (ISO 14040: 1997).

LCA is a tool through which we can assess all of the environmental impacts of a product, process or service throughout its life cycle. LCA help us do this assessment through:

- Building an inventory of all the energy and materials input and environmental consequences

- Assessing the potential environmental impact of all of these inputs and consequences

- Interpretation of the results to help the decision making process (Williams, 2009)

The precise identification of inputs, outputs and what is considered as life cycle is an important part of LCA. We should make sure to include all of the data related to relevant inputs, life cycle and outputs in our LCA study (Rebitzer et al., 2004; Williams, 2009). Below is a summary of what can be considered as inputs, stages of life cycle and outputs:

- Inputs: Trees and Crops/Water/Gas and Crude Oil/Chemicals/Energy/Capital Equipment

- Life Cycle: Raw Material Processing/Manufacturing/Production/Transportatio $\mathrm{n} /$ Product Life/Maintenance/Disposal 
- Outputs: Airborne Emissions/Recyclable Waste/Coproducts/Waterborne Emissions/Landfill Waste/Dumping and Littering

LCA consists of four main phases:

- Goal and scope definition

- Inventory Analysis

- Impact Assessment (LCIA)

- Interpretation (improvement assessment)

\section{Goal and Scope Definition}

The goal and scope definition phase is of great importance in every LCA study. In this phase, the reason as well as the depth and context of the LCA study is defined and elaborated (Rebitzer et al., 2004). There are several relevant concepts that need to be identified in goal and scope definition phase which are as followed:

- System boundaries (technical, geographic and time)

- Functional unit (or reference function)

- Rules and assumptions

- Type of impact assessment and valuation

- The groups to be addressed by the study

- $\quad$ Peer (Expert) review

\section{System Boundaries}

In the first phase of the LCA, the boundaries of the system that is going to be studied should be clearly defined; boundaries such as:

- The boundary between the system under study and the environment

- The boundaries between the system under study and other systems and

- The geographic and time boundaries. Infrastructure, technologies available and existing ecosystems are some of the factors that affect the geographic boundaries of a system. Also, time horizon is affected by pollutants' life span and other things such as technologies involved (SAIC, 2006)

\section{Functional Unit}

Functional unit is the measurement unit that is used in a LCA study so that a specific system or product can be compared to another system or product based on their environmental impacts and energy efficiency. For example, the functional unit for a paint system can be defined as the unit surface protected for 10 years or the functional unit for a refrigerator can be "a refrigerator" or "a refrigerator year" depending on the perspective of the LCA practitioner.

\section{Inventory Analysis}

Inventory analysis is the most developed as well as the most resource intensive part of LCA (Rebitzer et al., 2004; Williams, 2009). In the inventory analysis phase, all of the inflows and outflows generated by the system or product under study are identified and the data about each of these flows is collected per functional unit. Relevant data can be collected from several resources such as manufacturers' databases, government databases, previous LCAs, surveys and audits, test results. There are several software packages and databases that can be accessed for data collection (Williams, 2009). The important issue in data collection is that the data should be current and precise to avoid data gaps because data collected from one or several manufacturers or data collected from one specific country or region might not be a good representation of data required for another LCA study. So the validity and quality of data is of great significance.

The results from this phase are presented in an "Inventory Table". Inventory table depicts all of the inputs and outputs per functional unit (Klopffer, 1997). It generally includes inputs such as raw materials, energy and transportation, outputs such as air emissions, water waste and solid waste and other factors such as land use (Rebitzer et al., 2004; Williams, 2009).

\section{Life Cycle Impact Assessment (LCIA)}

Life Cycle Impact Assessment (LCIA) is the phase in which the potential impact of each of the aforementioned inflows and outflows is calculated. LCIA can serve as the basis for the comparison between different production systems based on their overall environmental impact. According to ISO, LCIA consists of three mandatory and three optional steps. The three mandatory stages are as follows (SAIC, 2006):

\section{Selecting and Defining the Impact Categories}

In this step, a list of environmental impact categories associated with the system is created. Impact categories can be divided into input related categories and output related categories. Table 3 indicates a list of categories adopted by SETAC-Europe:

\section{Classification}

Classification is the assigning of each of the parameters in the inventory table to their relative impact categories. For example, $\mathrm{CO} 2$ emissions can be classified under greenhouse gases category.

\section{Characterization}

In this step, the results obtained from the last phase are converted into a common unit of measurement within each category for the sake of simpler aggregation. 
Table 3. Impact categories according to SETAC-Europe

Impact Categories According

to SETAC-Europe

A: Input related categories

("resource depletion or completion"):

Abiotic resources (deposits, flows)

Biotic resources

Land

B: Output related categories ("pollution")

Greenhouse gases

Eutrophication

(including BOD and heat)

Odor

Noise

Radiation

Casualties

Human toxicological impact

Ecotoxicological impacts

Photo-oxidant formation

Acidification

Table 4. Toledo MSW breakdown (Franchetti and Kress, 2013)

\begin{tabular}{ll}
\hline Plastic type & $\begin{array}{l}\text { Amount collected } \\
\text { (Metric tons per year) }\end{array}$ \\
\hline Polyethylene Terephthalate (PETE) & 4,760 \\
High-Density Polyethylene (HDPE) & 1,550 \\
Low-Density Polyethylene (LDPE) & 930 \\
Other & 610 \\
Total & 7,850 \\
\hline
\end{tabular}

Through characterization, one can assign an impact indicator to each category so we can better compare different systems. The formulation used to calculate an impact indicator is as follows:

$$
\begin{gathered}
\text { Inventory Data } \times \text { Characterization Factor }=\text { Impact } \\
\text { Indicator }
\end{gathered}
$$

Characterization factors are constant numbers that are defined for a specific amount (e.g., one pound) of the given item. For example, Methane has a Global Warming Potential (GWP) of 21 per pound so if 10 pounds of Methane is released per functional unit, the total GWP for Methane equals $10 * 21=210$. We can find a uniform unit for all of the greenhouse gases using the same approach.

The three optional steps are defined as follows:

\section{Normalization}

Normalization is converting the potential impacts obtained from LCIA to a unit which provides us with the possibility of comparing different systems together (Nojabaei and Franchetti, 2014). For example, we can construct the ratio of the product's Global Warming Potential (GWP) to the national or regional GWP and then compare the products.

\section{Grouping}

It is the organizing of the impact factors based on geographical realm, company's priorities

\section{Weighting}

Is the ranking of potential impacts based on their importance. The problem with weighting is that it is subject to subjectivity because the ranking system used depends on several factors such as stakeholders' values, geographical conditions, the scale that is used (Nojabaei et al., 2012). For example, the importance of the "noise" factor can be much different in an urban location compared with an out-of-town location.

\section{Interpretation}

Interpretation is the final phase of a LCA study. In this phase, three major steps are performed (SAIC, 2006).

\section{Identifying the Important Issues based on the Results Obtained from Previous Phases}

In this step, the parameters, impact factors or life cycle stages that have the greatest influence on the results of the study are identified. There are three methods that can be used in order to identify the "significant issues": Contribution analysis, dominance analysis and anomaly assessment.

\section{Evaluating the Results Considering Completeness, Sensitivity and Consistency of the Data}

In this step, the validity and reliability of the data are examined. Completeness check, sensitivity check and consistency check are performed in this step.

\section{Conclusions and Recommendations}

In the last step, the results of the LCA study are reviewed and on the basis of the overall impact, conclusions about the more preferable system, products or process are made. Also, if determined by the scope of the study, recommendations are made about how to improve the system.

LCA is a tool designed for studying and comparing different products, services or processes based on their overall environmental impact throughout their life cycle. The ultimate goal of an LCA study is to help decision-makers select the better system from an environmental point of view. It is important to note that LCA cannot identify the best overall system by itself rather it should be used in simultaneity with other decision making tools because like any other tool, LCA has its own limitations. One of the most important limitations LCA has is that it does not take factors such as cost, performance or social and political factors into consideration e.g., a system with a lower overall environmental impact could be much costlier to set up. Also, one should be aware that the results of LCA studies can differ greatly based on the geographical region in which they are performed. For example, a LCA study done in the US might not be of so much help to practitioners in the Middle East. Therefore, it is essential to use LCA in the right context. 


\section{LCA in Waste Management}

An extensive literature is available on LCA studies for different waste management systems and the important issues that should be considered in this type of LCA application. These studies have been performed for different waste materials in different regions in the world and base their analyses on various impact categories.

Finnveden (1999) discusses five important issues that should be considered in an LCA application to waste management systems (Patel and Pandey, 2009). He argues that in order to be compatible with LCA definition, the system boundaries should be defined in a way that all products are "identical" in all of the systems. If so, one can exclude the stages that are common between all systems from the analysis. They also state that multi-input allocation is another issue that should be paid attention to. They argue that in performing life cycle inventory for different municipal waste management, the allocation process should be clear as to which emission or energy inputs and outputs are related to which material. Building more on this point, Barton (1996) introduces a "dual classification approach" for the LCI phase of an LCA for mixed waste management systems in which the input/output data is divided into two categories: Wasteindependent and waste-dependent. The paper argues that the potential impacts associated with different types of materials present in the mixed municipal waste should be identified and properly allocated to the different materials. Speaking more to this point, Clift et al. (2000) also discuss the problem of allocation in LCA applications to Integrated Waste Management (IWS) systems. They argue that there should be a clear distinction between "waste-related" emissions which depend on the waste composition and "process-related" emissions which are produced directly by the waste management operations (Clift et al., 2000).

The issue of allocation in applying LCA to integrated waste management systems has been the subject of much debate. To avoid the complications arising from studying mixed waste streams, scholars have been trying to apply LCA to material-specific treatment options where possible i.e., they study different waste treatment systems for one specific material type. The emergence of material-specific recovery methods has enabled researchers to avoid the allocation problem and have a clear-cut inventory analysis.

Molgaard (1995) used LCA to compare six alternatives for recycling plastics. Material recycling with separation based on vision or chemical analysis, material recycling with separation based on selective dissolution, material recycling without separation, pyrolysis, incineration with heat recovery and landfilling were the six methods studied in Molgaard's work. Molgaard used the concept of "Eco-profile" in his study which is an approach based on LCA that provides the ability to rank the alternatives based on certain impact categories. The impact categories used in this study were environmental effects (gaseous emission) and resource consumption (crude oil, natural gas and pit coal).

Several other LCA studies have been carried out for plastic recycling systems. Two case studies for plastic packaging wastes carried out by (Arena et al., 2003) showed that recycling scenarios offer considerable environmental benefits compared to non-recycling scenarios (Perugini et al., 2005). A similar research has been done by (Wollny et al., 2001) using a case study in Germnay. Shen et al. (2010) performed an LCA study on four different PET bottles to fiber recycling systems (mechanical and semi-mechanical). The study shows that all of the studied recycling systems offer substantial non-renewable energy and Global Warming Potential (GWP) savings.

Another flaw associated with LCA that has been discussed extensively is its inability to incorporate economic and social impacts into its analyses. Assies argues that social and other economic assessments of a product lifecycle would be useful in the policy-making arena. In fact, economic and social implications of a systems is sometimes more important than its environmental impacts from a decision making point of view. In an effort to address this issue, scholars have tried to incorporate different forms of economic evaluation into their studies. These methods are developed to accompany the LCA environmental results in order to provide a comprehensive comparison of the different systems studied for the decision-makers.

Simple economic evaluation that includes costs and benefits of different scenarios has been carried out in several works (Malakahmad et al., 2013; Aye and Widjaya, 2006; Wollny et al., 2001). These works consider land acquisition costs, transportation costs, equipment costs as negative costs whilst considering revenues generated by selling the recycled materials and savings in energy and raw material as benefits.

Craighill and Powell (1996) utilize a new method named "Lifecycle Evaluation" in their study. "Lifecycle Evaluation" is a combination of LCA and economic evaluation. In their study, they perform an environmental an economic comparison between recycling and conventional waste disposal systems (landfilling and incineration) for different materials through a case study of Milton Keynes in Central England. Their study considers global warming potential, acidification and nitrification as the main impact categories for LCA inventory. Monetary estimates of gaseous emissions, road traffic accident casualties and road congestion were used as parameters for the economic evaluation.

Norris (2001) points out the inability of LCA methodology in incorporating economic implications of 
different systems which it studies. He argues that the "economic consequences" of a system are eventually going to play an important role in the decision making process and so they are not negligible. Norris proposes the use of Life Cycle Costing (LCC) as a method to be integrated into the LCA methodology and introduces the following two approaches used for integrating full LCA and full LCC: PTLaser and PTAce.

Reich (2001) introduces Life Cycle Costing (LCC) as a means to complement the environmental results from the LCA. In his paper, he tests the use of LCC as a tool for economic evaluation of waste management systems through a case study (Reich, 2001). LCC is a method of studying the costs associated with a product or service systems throughout the system boundaries. Reich breaks down the LCC methodology into two parts for his study: Financial LCC and environmental LCC. Financial LCC accounts for all of the direct costs incurred by fulfilling the functional unit. Examples of these costs would be investment cost, operating costs and profit (a negative cost). Environmental LCC is a tool to aggregate the monetary values of the environmental emissions generated by the system. Reich applies LCC to eight waste management scenarios and gives a holistic evaluation of the scenarios both from an environmental and an economic standpoint.

\section{Methodology and Calculations}

\section{Region}

The region chosen for this study is Toledo, Ohio. Toledo, Ohio is a city located in Northwest Ohio with a population of 284,012 and expands over an area of $217.87 \mathrm{~km}^{2}$. Waste collection data for the region was collected from the Lucas County Solid Waste Management District (LCWMD). There is currently 20 drop off sites operating within the city of Toledo. The LCWMD facility collect recyclable materials such as plastic, paper, cardboard from the drop off sites and deliver them to recycling facilities after sortation.

LCWMD collects 8,700 metric tons of solid waste annually. Mixed plastic waste composes $90 \%$ of the total solid waste collection which is equal to 7,850 metric tons. Table 4 shows the composition of plastic waste by plastic type.

\section{Life Cycle Analysis}

The six plastic sorting technologies are compared using Economic Input-Output Life Cycle Assessment (EIO-LCA). The Economic Input-Output Life Cycle Assessment (EIO-LCA) method estimates the materials and energy resources required for and the environmental emissions resulting from activities in our economy (Fig. 1).

\section{Scope}

The system boundary for this study encompasses the installation/manufacturing processes and the transportation processes to/from the facility. This allows us to focus on economic, energy and environmental aspects of each system and disregard the communal stages between the systems. Figure 2 displays the stages considered in this study.

\section{Functional Unit}

In LCA studies, the functional unit serves as a reference for comparison between multiple systems. Functional unit should clearly define what is being studied and must be selected in a way that all of the inputs and outputs can be assigned with regards to it.

The functional unit chosen for this study is the total amount of plastic waste generated in the region which is equal to 7,850 metric tons of comingled plastic waste.

\section{Life Cycle Inventory}

Energy requirements and carbon footprint are the two main impact categories selected for this study. Carbon footprint data include carbon emissions incurred from installing and operating the manufacturing systems as well as the carbon emissions generated by transporting the waste from drop-off sites to the sorting facility for a 10 year period.

Energy data include the equivalent amounts of energy required to set up and operate the manufacturing systems in addition to the energy required for the transportation processes in each of the manufacturing systems over a 10 year period.

\section{Economic Analysis}

Cost related data for each scenario were obtained through contacting local vendors and were divided into two sections:

- Initial investment: The amount of monetary investment needed to purchase and install the required equipment to operate a sorting facility with a capacity of 10000 metric tons of plastic per year

- Annual operating costs: The annual costs of running a plastic sorting facility with a capacity of 10000 metric tons of plastic per year. This includes labor, material, energy, transportation and maintenance costs

An economic life of 10 years is chosen for this research which is based on the equipment class life introduced by the US Internal Revenue System (IRS) for the required equipment.

The economic feasibility of the scenarios is then compared using Internal Rate of Return (IRR) and payback period analyses. IRR is an economic indicator of project's attractiveness with higher values 
of IRR corresponding to more financially desirable projects. The formula used to calculate the IRR of each project is Equation 1:

$$
N P V=\sum_{t=0}^{n} C_{t} /((1+r) \exp t)=0
$$

where, $N P V$ stands for net present value; $C_{t}$ represents the cash flow of the evaluated scenario minus the cash flow of the standard scenario for yeat $t ; t$ is the economic life considered in years and $r$ is the interest rate or IRR of the scenario. In this method, NPV of each scenario is set equal to 0 and then the above equation is solved for $r$. The obtained $r$ is the IRR of the scenario. Scenario 1 was chosen as the standard scenario and $C_{t}$ for each scenario is evaluated with respect to this scenario. For better comparison, payback periods are also calculated for each scenario. Payback period is the period of time in which the initial investment is compensated for through the aggregation of revenues. Economically, shorter payback periods are preferable since it means that the system regains its initial costs in a shorter amount of time.

\section{Results}

\section{Calculation and Assumptions}

Table 5 depicts the results. All of the cost, energy and carbon emissions data for each scenario were collected through contacting local vendors and getting their estimates.

It is assumed that the waste is delivered once daily to the sorting facility from each of the 20 community drop-off sites whose distance from the sorting facility ranges from 5 to $20 \mathrm{~km}$.

The emission data is reported in million Metric Tons of Carbon Dioxide Equivalent (MTCO2E). MTCO2E is a measure that aggregates various greenhouse gas emissions into one single measure and is widely used in LCA studies as a measure to compare the Global Warming Potential (GWP) of different systems.

\section{Scenario 1: Electrostatic Separation}

The data were collected by contacting two local vendors and getting their estimates. The average initial cost reported by the vendors was $\$ 3.1$ million which is the cost of purchasing the required buildings and equipment for a processing plant with a capacity of 10000 metric tons per year. Additionally, it was estimated that $1.48 \mathrm{GJ}$ of energy would be required to set up the system while 288.01 MTCO2E would be generated during the process in terms of carbon emissions. The average annual cost of operating the system was estimated to be $\$ 1.8$ million which includes the salaries and benefits for two administrative staff and ten workers as well as the system material, energy, maintenance and transportation costs. The annual operational energy use and carbon emission were estimated $0.046 \mathrm{GJ}$ and 8.95 MTCO2E, respectively and are assumed to be generated by the local coal power plant. Consequently, the system would require $0.46 \mathrm{GJ}$ of energy and would omit 89.5 MTCO2E of carbon emissions in a 10 year timeframe. The annual energy consumption for transportation processes is calculated at a rate of $4.25 \mathrm{~km} /$ liter and $38.7 \mathrm{MJ}$ per liter which sums up to $0.084 \mathrm{GJ}$ per year and $0.840 \mathrm{GJ}$ over the ten year timeframe. This resulted in net energy usage of $1.94 \mathrm{GJ}$ and 377.524 MTCO2EE over the ten year life of the system. The system would sort 7,800 metric tons of plastic each year which considering an average per metric ton price of separated plastics of $\$ 300$ would generate $\$ 2.35$ million of revenue per year.

\section{Scenario 2: Sink/Swim Differential Method}

The data were collected by contacting two local vendors and getting their estimates. The average initial cost reported by the vendors was $\$ 2.75$ million which is the cost of purchasing the required buildings and equipment for a processing plant with a capacity of 10000 metric tons per year. Additionally, it was estimated that $1.35 \mathrm{GJ}$ of energy would be required to set up the system while 262.71 MTCO2E would be generated during the process in terms of carbon emissions. The average annual cost of operating the system was estimated to be $\$ 1.75$ million which includes the salaries and benefits for two administrative staff and ten workers as well as the system material, energy, maintenance and transportation costs. The annual operational energy use and carbon emission were estimated 0.042 GJ and 8.17 MTCO2E, respectively and are assumed to be generated by the local coal power plant. Consequently, the system would require $0.42 \mathrm{GJ}$ of energy and would omit 81.7 MTCO2E of carbon emissions in a 10 year timeframe. The annual energy consumption for transportation processes is calculated at a rate of 4.25 $\mathrm{km} /$ liter and 38.7 MJ per liter which sums up to 0.084 GJ per year and 0.840 GJ over the ten year timeframe. This resulted in net energy usage of $1.77 \mathrm{GJ}$ and 344.442 MTCO2EE over the ten year life of the system. The system would sort 7,800 metric tons of plastic each year which considering an average per metric ton price of separated plastics of $\$ 300$ would generate $\$ 2.35$ million of revenue per year.

\section{Scenario 3: Surfutant Based Seperation}

The data were collected by contacting two local vendors and getting their estimates. The average initial cost reported by the vendors was $\$ 2.6$ million which is the cost of purchasing the required buildings and equipment for a processing plant with a capacity of 10000 metric tons per year. 


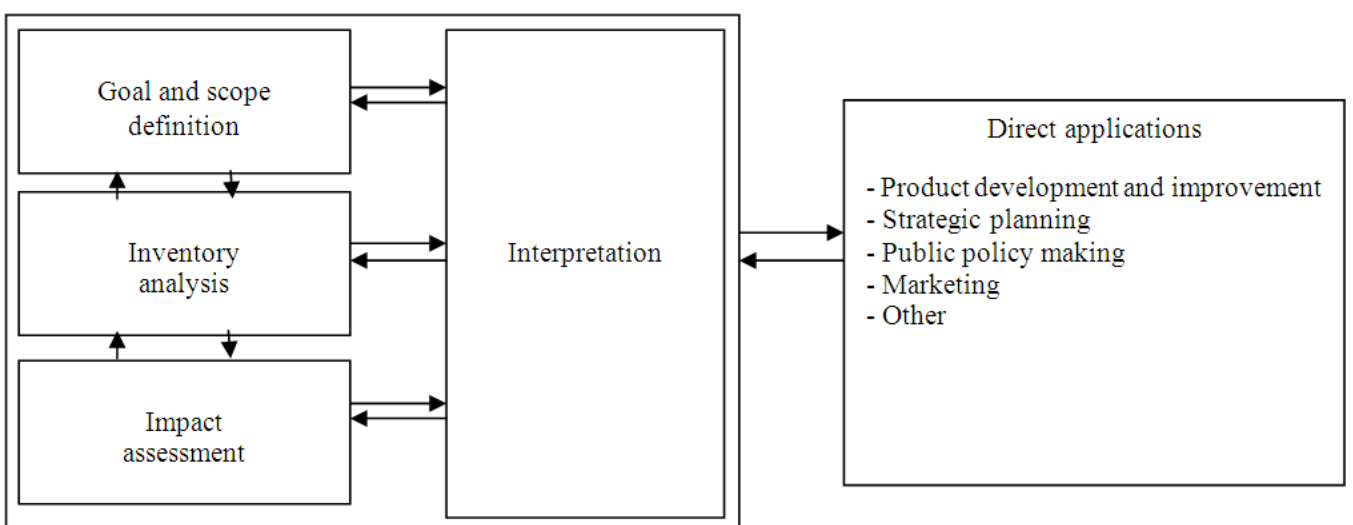

Fig. 1. LCA Phase

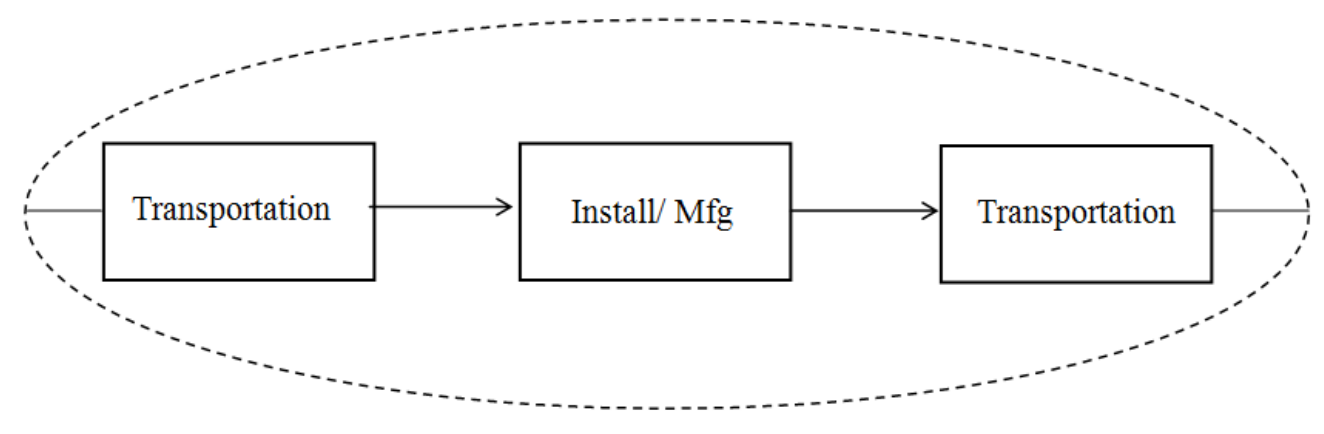

Fig. 2. System boundaries

Table 5. Cost, energy and $\mathrm{CO} 2$ emissions for the six scenarios

\begin{tabular}{lllllll}
\hline & $\begin{array}{l}\text { Scenario 1 } \\
\text { electrostatic }\end{array}$ & $\begin{array}{l}\text { Scenario 2 } \\
\text { differential }\end{array}$ & $\begin{array}{l}\text { Scenario 3 } \\
\text { surfactant }\end{array}$ & $\begin{array}{l}\text { Scenario 4 } \\
\text { infrared }\end{array}$ & $\begin{array}{l}\text { Scenario 5 } \\
\text { ultrasound }\end{array}$ & $\begin{array}{l}\text { Scenario 6 } \\
\text { EM-Ferro }\end{array}$ \\
\hline Cost & $\$$ & $\$$ & $\$$ & $\$$ & $\$$ & $\$$ \\
Initial cost of system & $3,100,000$ & $2,750,000$ & $2,600,000$ & $2,800,000$ & $3,300,000$ & $2,650,000$ \\
Annual operational cost of system & $-1,800,000$ & $-1,750,000$ & $-1,850,000$ & $-1,700,000$ & $-1,750,000$ & $-1,750,000$ \\
Annual revenue from system & $2,350,000$ & $2,350,000$ & $2,350,000$ & $2,350,000$ & $2,350,000$ & $2,350,000$ \\
Net annual cost benefit & 550,000 & 600,000 & 500,000 & 650,000 & 600,000 & 600,000 \\
Payback period (years) & 5.64 & 4.58 & 5.2 & 4.31 & 5.5 & 4.42 \\
Internal rate of return & $12 \%$ & $17 \%$ & $14 \%$ & $19 \%$ & $13 \%$ & $18 \%$ \\
Energy & GJ & GJ & GJ & GJ & GJ & GJ \\
Initial installment energy use & -1.48 & -1.35 & 1.38 & -1.41 & -1.54 & -1.38 \\
Annual operational energy use & -0.046 & -0.042 & -0.044 & -0.047 & -0.046 & -0.045 \\
Net energy use over 10 years & -1.94 & -1.77 & -1.82 & -1.88 & -2 & -1.83 \\
Carbon Emissions & MTCO2E & MTCO2E & MTCO2E & MTCO2E & MTCO2E & MTCO2E \\
Initial installment emissions & 288.01 & 262.71 & 268.55 & 274.39 & 299.68 & 268.55 \\
Annual operational emissions & 8.95 & 8.17 & 8.56 & 9.15 & 8.95 & 8.76 \\
Total emissions over 10 year life & 377.524 & 344.442 & 354.172 & 365.848 & 389.2 & 356.118 \\
\hline
\end{tabular}

Additionally, it was estimated that 1.38 GJ of energy would be required to set up the system while 268.55 $\mathrm{MTCO} 2 \mathrm{E}$ would be generated during the process in terms of carbon emissions. The average annual cost of operating the system was estimated to be $\$ 1.85$ million which includes the salaries and benefits for two administrative staff and ten workers as well as the system material, energy, maintenance and transportation costs. The annual operational energy use and carbon emission were estimated 0.044 GJ and 8.56 MTCO2E, respectively and are assumed to be generated by the local coal power plant. Consequently, the system would require 0.44 GJ of energy and would omit 85.6 MTCO2E of carbon emissions in a 10 year timeframe. The annual energy consumption for transportation processes is calculated at a rate of $4.25 \mathrm{~km} /$ liter and 38.7 MJ per liter 
which sums up to 0.084 GJ per year and 0.840 GJ over the ten year timeframe. This resulted in net energy usage of $1.82 \mathrm{GJ}$ and 354.172 MTCO2EE over the ten year life of the system. The system would sort 7,800 metric tons of plastic each year which considering an average per metric ton price of separated plastics of $\$ 300$ would generate $\$ 2.35$ million of revenue per year.

\section{Scenario 4: Infra-red Scanning}

The data were collected by contacting two local vendors and getting their estimates. The average initial cost reported by the vendors was $\$ 2.8$ million which is the cost of purchasing the required buildings and equipment for a processing plant with a capacity of 10000 metric tons per year. Additionally, it was estimated that $1.41 \mathrm{GJ}$ of energy would be required to set up the system while 274.39 MTCO2E would be generated during the process in terms of carbon emissions. The average annual cost of operating the system was estimated to be $\$ 1.7$ million which includes the salaries and benefits for two administrative staff and ten workers as well as the system material, energy, maintenance and transportation costs. The annual operational energy use and carbon emission were estimated 0.047 GJ and 9.15 MTCO2E, respectively and are assumed to be generated by the local coal power plant. Consequently, the system would require $0.47 \mathrm{GJ}$ of energy and would omit 91.5 MTCO2E of carbon emissions in a 10 year timeframe. The annual energy consumption for transportation processes is calculated at a rate of $4.25 \mathrm{~km} /$ liter and $38.7 \mathrm{MJ}$ per liter which sums up to $0.084 \mathrm{GJ}$ per year and $0.840 \mathrm{GJ}$ over the ten year timeframe. This resulted in net energy usage of $1.88 \mathrm{GJ}$ and $365.848 \mathrm{MTCO} 2 \mathrm{EE}$ over the ten year life of the system. The system would sort 7,800 metric tons of plastic each year which considering an average per metric ton price of separated plastics of $\$ 300$ would generate $\$ 2.35$ million of revenue per year.

\section{Scenario 5: Ultrasound Scanning}

The data were collected by contacting two local vendors and getting their estimates. The average initial cost reported by the vendors was $\$ 3.3$ million which is the cost of purchasing the required buildings and equipment for a processing plant with a capacity of 10000 metric tons per year. Additionally, it was estimated that $1.54 \mathrm{GJ}$ of energy would be required to set up the system while 299.68 MTCO2E would be generated during the process in terms of carbon emissions. The average annual cost of operating the system was estimated to be $\$ 1.75$ million which includes the salaries and benefits for two administrative staff and ten workers as well as the system material, energy, maintenance and transportation costs. The annual operational energy use and carbon emission were estimated 0.046 GJ and 8.95 MTCO2E, respectively and are assumed to be generated by the local coal power plant. Consequently, the system would require 0.46 GJ of energy and would omit 89.5 MTCO2E of carbon emissions in a 10 year timeframe. The annual energy consumption for transportation processes is calculated at a rate of $4.25 \mathrm{~km} /$ liter and $38.7 \mathrm{MJ}$ per liter which sums up to $0.084 \mathrm{GJ}$ per year and $0.840 \mathrm{GJ}$ over the ten year timeframe. This resulted in net energy usage of 2.00 GJ and 389.2 MTCO2EE over the ten year life of the system. The system would sort 7,800 metric tons of plastic each year which considering an average per metric ton price of separated plastics of $\$ 300$ would generate $\$ 2.35$ million of revenue per year.

\section{Scenario 6: EM-Ferro}

The data were collected by contacting two local vendors and getting their estimates. The average initial cost reported by the vendors was $\$ 2.65$ million which is the cost of purchasing the required buildings and equipment for a processing plant with a capacity of 10000 metric tons per year. Additionally, it was estimated that $1.38 \mathrm{GJ}$ of energy would be required to set up the system while 268.55 MTCO2E would be generated during the process in terms of carbon emissions. The average annual cost of operating the system was estimated to be $\$ 1.75$ million which includes the salaries and benefits for two administrative staff and ten workers as well as the system material, energy, maintenance and transportation costs. The annual operational energy use and carbon emission were estimated $0.045 \mathrm{GJ}$ and 8.76 MTCO2E, respectively and are assumed to be generated by the local coal power plant. Consequently, the system would require $0.45 \mathrm{GJ}$ of energy and would omit 87.6 MTCO2E of carbon emissions in a 10 year timeframe. The annual energy consumption for transportation processes is calculated at a rate of $4.25 \mathrm{~km} /$ liter and $38.7 \mathrm{MJ}$ per liter which sums up to $0.084 \mathrm{GJ}$ per year and $0.840 \mathrm{GJ}$ over the ten year timeframe. This resulted in net energy usage of $1.83 \mathrm{GJ}$ and 356.118 MTCO2EE over the ten year life of the system. The system would sort 7,800 metric tons of plastic each year which considering an average per metric ton price of separated plastics of $\$ 300$ would generate $\$ 2.35$ million of revenue per year.

It should be noted that the energy use data for transportation is excluded because it is a communal stage for all of the scenarios.

\section{Economic Analysis}

Figure 3 compares the internal rate of returns of the six scenarios. As discussed before, IRR is a measure that is used to evaluate and compare the financial attractiveness of projects. 


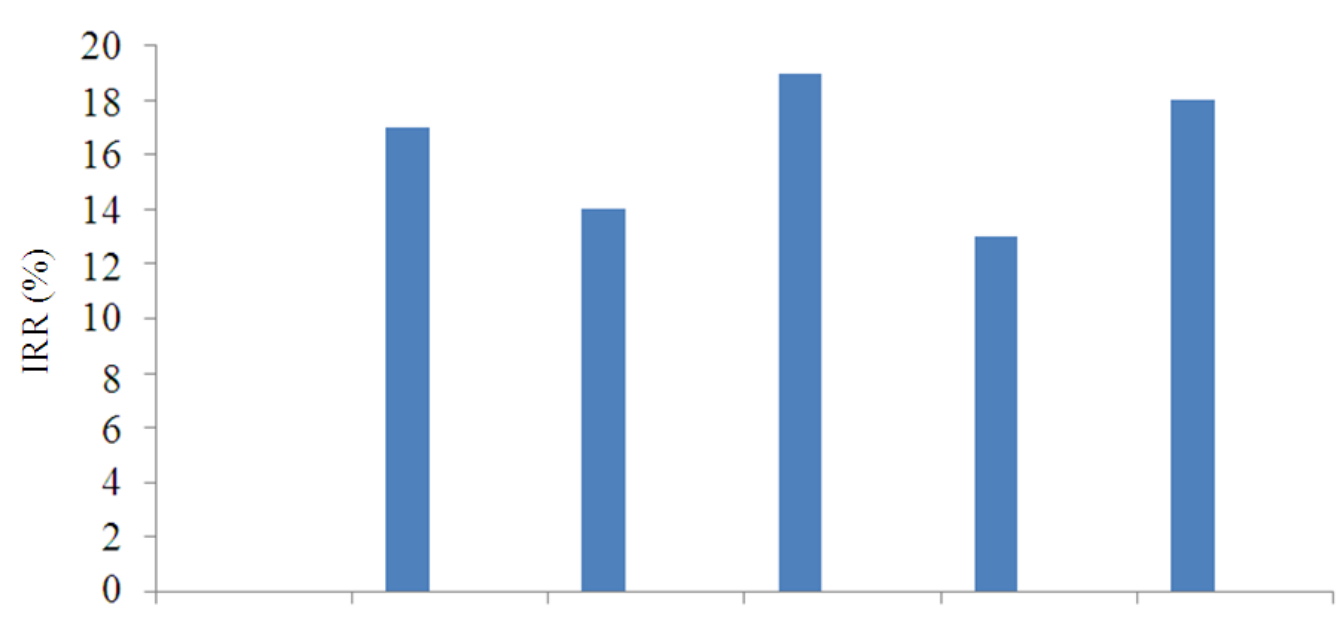

Scenario 1 Scenario 2 Scenario 3 Scenario 4 Scenario 5 Scenario 6

Fig. 3. Internal rate of return of the six scenarios

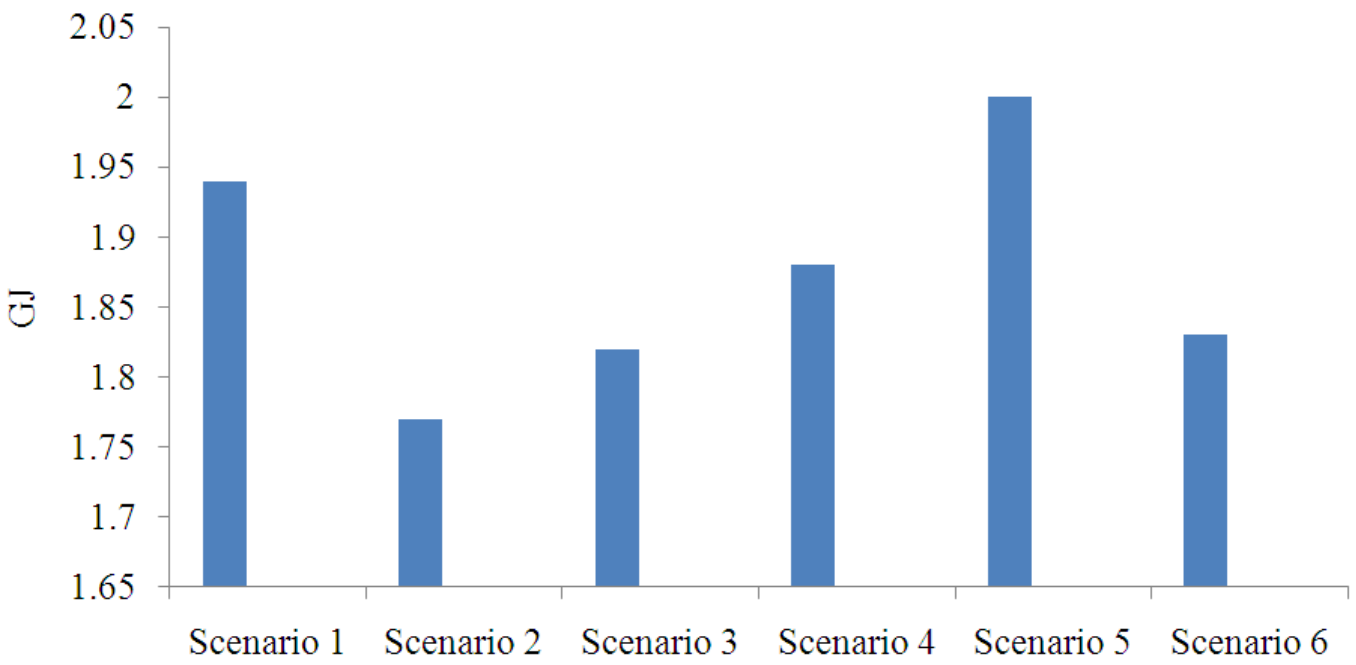

Fig. 4. Energy use over 10 year lifetime

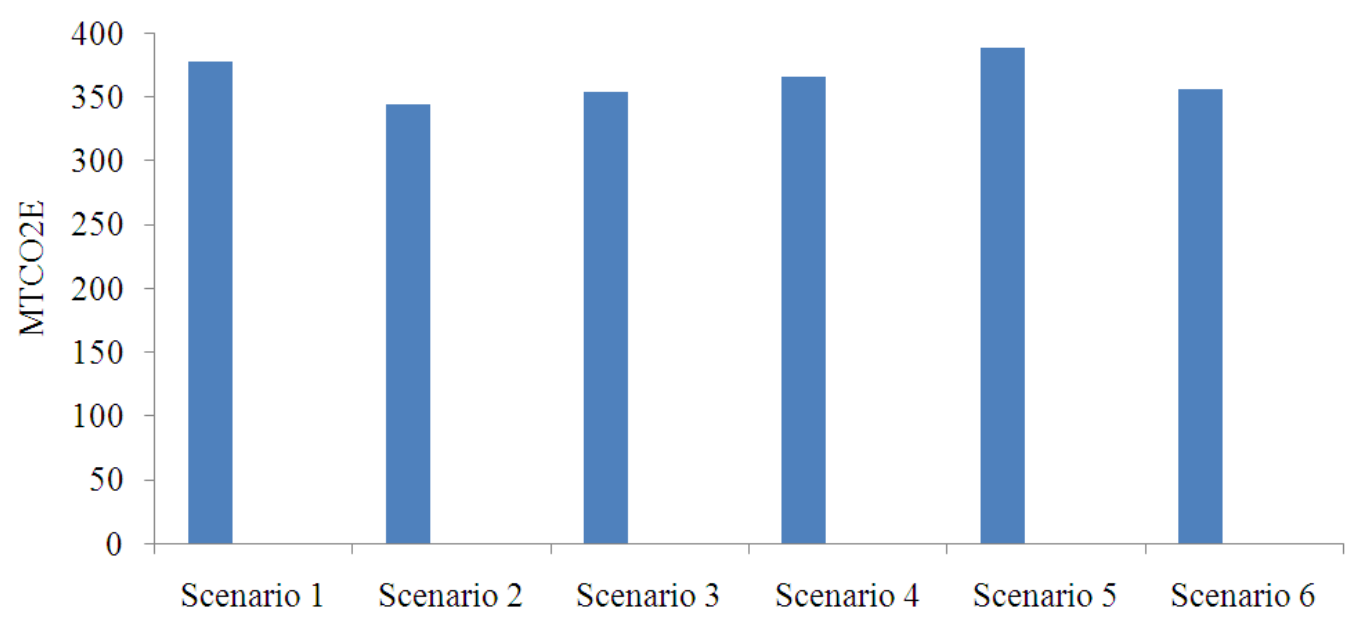

Fig. 5. Total carbon emissions over 10 year lifetime 
Obviously, scenario 4 and 6 are the most attractive ones from an economic standpoint whereas scenario 1 and scenario 5 have the weakest financial performance which is partly due to the larger initial investments that are required to install the systems. Scenario 4 also has the least annual operational cost while the largest annual operational cost belongs to scenario 3 which is due to the operational (surfactants) requirements. Ranking of the scenarios in terms of financial attractiveness from highest to lowest is Scenario $4>$ Scenario 6> Scenario 2> Scenario 3> Scenario 5> Scenario 1 .

\section{Energy Analysis}

Figure 4 shows the total energy consumption of the scenarios over 10 years. The net energy use of the systems ranges from $1.77 \mathrm{GJ}$ to $2.00 \mathrm{GJ}$ for a 10 year lifetime. Scenario 2 is the least energy intensive technology compared to other technologies. This is due to the fact that scenario 2 utilizes less energy intensive equipment (pumps) compared to other methods. Scenario 5 (ultrasound) is the most energy intensive method because of the mechanical and electronic equipment needs. Ranking of the scenarios in terms of energy consumption from lowest to highest is Scenario $2>$ Scenario $3>$ Scenario 6> Scenario $4>$ Scenario $1>$ Scenario 5 .

\section{Environmental Analysis}

Figure 5 displays the environmental performances of the scenarios in terms of carbon emissions. Carbon emissions are the result of transporting the plastic waste to/from the facility as well as the energy consumed by the equipment which is generated by the local coal power plant. Ranking of the scenarios in terms of carbon emissions from lowest to highest is Scenario $2>$ Scenario 6> Scenario 3> Scenario $4>$ Scenario $4>$ Scenario 5. The variation in carbon emissions between the scenarios arises from the difference in equipment and energy use to install and operate the systems.

\section{Discussion}

The data congregated display the economic and environmental performance of the six post-consumer plastic sortation technologies. Economically, all of the scenarios have positive economic performances with IRRs ranging from $12 \%$ to $19 \%$; however, over a 10 year period, scenario 4 (infrared) has the best economic performance with a total cost benefit of $\$ 3.7$ million and an IRR of $19 \%$ whereas scenario 1 (electrostatic) is the least attractive from an economic point of view.

The energy consumption data shows that scenario 2 (differential sink/swim) offers the most saving in terms of energy with a total energy usage of 1.77 GJ over a 10 year life period.
The environmental analysis shows that all of the scenarios generate almost the same level of carbon emissions; however, scenario 2 is the most preferable scenario from an environmental standpoint with a total carbon emission of 344.442 MTCO2E over a 10 year life period.

The analyses in this paper is limited to the transportation and manufacturing phases of each scenario; however, further research needs to be carried out to provide a more comprehensive analysis. It is important to notice that the EM-Ferro method is still under development and improvement to reach its optimum success rate. Having known the success rates, the boundaries of the study can be broadened to encompass the avoided burdens of each scenario and cost, energy and $\mathrm{CO} 2$ emission related inputs and outputs corresponding to the disposal of unsorted plastics for each scenario.

\section{Conclusion}

This study compared six emerging post-consumer plastic sortation technologies in the three categories of cost, energy and $\mathrm{CO} 2$ emissions via a case study. The data obtained were for 7,850 metric tons of plastic that is collected annually in the city of Toledo from 20 drop off sites. The method used in this study is Economic InputOutput LCA (EIO-LCA) method which provided a comprehensive account for all of the related initial and startup cost, energy and $\mathrm{CO} 2$ emissions data for each of the six scenarios for a 10 year period lifetime. In order to compare the scenarios fro an economic point of view, IRRs and payback periods were calculated for all of the scenarios. The economic analysis showed that all of the scenarios have positive economic performances with IRR s ranging from 12 to $19 \%$. Over a 10 year period, scenario 4 (infrared) is most preferred scenario from an economic standpoint with a total cost benefit of $\$ 3.7$ million and an IRR of 19\% (Table 5).

The energy data showed that scenario 2 (differential sink/swim) uses the least energy over a 10 year lifetime. With regards to carbon emission, all pf the scenarios have similar performances with total emissions over 10 year time ranging from 344.442 MTCO2EE to 389.2 MTCO2EE. From a mere environmental point of view, scenario 2 has the best environmental performance.

The results also show that scenario 6 (EM-Ferro) offers substantial cost and environmental benefits on a larger scale and it can compete with other technologies that are currently in use. The standings of this method in the three categories show that with further improvements in performance and output, it could be widely applicable in the recycling industry.

The results of the analysis show that all of studied scenarios are economically viable. They also provide 
rankings for three categories; however, further research needs to be carried out to provide a more comprehensive analysis. It is important to notice that the EM-Ferro method is still under development and improvement to reach its optimum success rate. Having known the success rates, the boundaries of the study can be broadened to encompass the avoided burdens of each scenario and cost, energy and $\mathrm{CO} 2$ emission related inputs and outputs corresponding to the disposal of unsorted plastics for each scenario.

\section{Acknowledgment}

My special thanks go to The University of Toledo for providing research fund.

\section{Author's Contributions}

Seyedehfarzaneh Nojabaei: Designed the research plan and organized the study.

Omid Nematshahi: Participated in all experiments, coordinated the data-analysis.

Matthew Franchetti: Coordinated the work.

\section{Ethics}

Ethical standards of conduct in research and ethical standards in the publication of academic journal have been observed.

\section{References}

Al-Salem, S.M., P. Lettieri and J. Baeyens, 2009. Recycling and recovery routes of Plastic Solid Waste (PSW): A review. Waste Manage., 29: 2625-2643. DOI: 10.1016/j.wasman.2009.06.004

Arena, U., M.L. Mastellone and F. Perugini, 2003. Life cycle assessment of a plastic packaging recycling system. Int. J. Life Cycle Assess., 8: 92-98. DOI: 10.1007/BF02978432

Aye, L. and E.R. Widjaya, 2006. Environmental and economic analyses of waste disposal options for traditional markets in Indonesia. Waste Manage., 26: $1180-1191$.

DOI: 10.1016/j.wasman.2005.09.010

Barton, J.R., 1996. Life cycle assessment for waste management. Waste Manage., 16: 35-50. DOI: $10.1016 / \mathrm{S} 0956-053 \mathrm{X}(96) 00057-8$

Clift, R., A. Doig and G. Finnveden, 2000. The application of life cycle assessment to integrated solid waste management: Part 1-methodology. Sustainable Develop., 78: 279-287. DOI: $10.1205 / 095758200530790$

Craighill, A.L. and J.C. Powell, 1996. Lifecycle assessment and economic evaluation of recycling: A case study. Resources Conservat. Recycl., 17: 75-96. DOI: 10.1016/0921-3449(96)01105-6
Dodbiba, G., J. Sadaki, A. Shibayama and T. Fujita, 2006. Sorting techniques for plastics recycling. Chinese J. Process Eng., 06: 186-191.

EPA, 2014a. Wastes-resource conservation: Plastics.

EPA, 2014b. Wastes-resource conservation-common wastes and materials. EPA.

Finnveden, G., 1999. Methodological aspects of life cycle assessment of integrated solid waste management systems. Resources, Conservat. Recycl., 26: 173-187. DOI: 10.1016/S0921-3449(99)00005-1

Franchetti, M. and C. Kress, 2013. Case study of economic and environmental analysis of five postconsumer plastic sortation methods. Int. J. Waste Manage. Technol., 1: 67-76.

Klopffer, W., 1997. Life cycle assessment. Environ. Sci. Pollution Res. Int., 4: 223-228. DOI: $10.1007 / \mathrm{BF} 02986351$

Malakahmad, A., S. Nasrudin, N.E.A. Basri and S.M. Zain, 2013. Anaerobic transformation of biodegradable waste; simultaneous production of energy and fertilizer. Am. J. Environ. Sci., 9: 113-119.

DOI: 10.3844/ajessp.2013.113.119

Molgaard, C., 1995. Environmental impacts by disposal of plastic from municipal solid waste. Resources Conservat. Recycl., 15: 51-63. DOI: 10.1016/0921-3449(95)00013-9

Nojabaei, S. and M. Franchetti, 2014. Case study of the optimizing the automotive manufacturing systems efficiency via applying new method of scheduling. Am. J. Eng. Applied Sci., 7: 282-291. DOI: 10.3844/ajeassp.2014.282.291

Nojabaei, S., Z. Leman, S.H. Tang and S. Sulaiman, 2012. Development of priority oriented scheduling method to increase the reliability of manufacturing systems. Am. J. Applied Sci., 9: 1435-1442. DOI: 10.3844 /ajassp.2012.1435.1442

Norris, G.A., 2001. Integrating life cycle cost analysis and LCA. Int. J. Life Cycle Assess., 6: 118-120. DOI: $10.1007 / \mathrm{BF} 02977849$

Patel, H. and S. Pandey, 2009. Exploring the reuse potential of chemical sludge from textile wastewater treatment plants in India-A Hazardous Waste. Am. J. Environ. Sci., 5: 106-110. DOI: 10.3844/ajessp.2009.106.110

Perugini, F., M.L. Mastellone and U. Arena, 2005. A life cycle assessment of mechanical and feedstock recycling options for management of plastic packaging wastes. Environ. Progress, 24: 137-154. DOI: $10.1002 /$ ep. 10078

Pongstabodee, S., N. Kunachitpimol and S. Damronglerd, 2008. Combination of three-stage sink-float method and selective flotation technique for separation of mixed post-consumer plastic waste. Waste Manage., 28: 475-483.

DOI: 10.1016/j.wasman.2007.03.005 
Rebitzer, G., T. Ekvall, R. Frischknecht, D. Hunkeler and G. Norris et al., 2004. Life cycle assessment: Part 1: Framework, goal and scope definition, inventory analysis and applications. Environ. Int., 30: 701-720. DOI: 10.1016/j.envint.2003.11.005

Reich, M.C., 2001. Economic assessment of municipal waste management systems-case studies using a combination of Life Cycle Assessment (LCA) and Life Cycle Costing (LCC). Environ. Assess. Waste Manage., 13: 253-263.

SAIC, 2006. Life-cycle Assessment: Principles and practice. Scientific Applications International Corporation.

Shen, L., E. Worrell and M.K. Patel, 2010. Open-loop recycling: A LCA case study of PET bottle-to-fibre recycling. Resources Conservat. Recycl., 55: 34-52. DOI: 10.1016/j.resconrec.2010.06.014
Vijaya, S., A.N. Ma and Y.M. Choo, 2009. A gate to gate assessment of environmental performance for production of crude palm kernel oil using life cycle assessment approach. Am. J. Environ. Sci., 5: 267-272. DOI: 10.3844/ajessp.2009.267.272

Williams, A.S., 2009. Life cycle analysis: A step by step approach. Institute of Natural Resource Sustainability, University of Illinois at UrbanaChampaign: Urbana, USA.

Wollny, V., G. Dehoust, U.R. Fritsche and P. Weinem, 2001. Comparison of plastic packaging waste management options: Feedstock recycling versus energy recovery in Germany. J. Ind. Ecol., 5: 49-63. DOI: $10.1162 / 108819801760049468$ 